\title{
Expanding the Evidence for Aerosol Therapy During Noninvasive Ventilation
}

Noninvasive ventilation (NIV) is the administration of ventilatory support without using an invasive artificial airway. It is commonly utilized as an alternative to invasive ventilation to treat respiratory failure. NIV is being used in an expanding list of indications. It is safe and effective in adult and pediatric patients, and it has gained increasing popularity. ${ }^{1}$ In the pediatric ICU, NIV can be used for a broad range of conditions including acute respiratory failure, asthma, and other indications. ${ }^{2}$ In addition, NIV has become a first-line therapy for upper airway obstruction. ${ }^{3}$

Aerosol therapy is commonly used in patients with obstructive lung disease requiring NIV. ${ }^{4}$ NIV alters the pattern of gas flow entering the airway, which affects the transport of the inhaled aerosol. ${ }^{5}$ However, few studies have reported the best procedure for aerosol delivery with NIV, and most of these studies have focused on adult subjects. ${ }^{5-7}$ Pediatric research pertaining to aerosol delivery is lacking. Due to the anatomy of the pediatric airway, the aerosol delivery procedures used in adults cannot be applied to children. Consequently, exploring an effective pediatric aerosol inhalation regimen will provide clinical benefits to children requiring NIV.

In this issue of Respiratory CARE, Velasco and Berlinski $^{8}$ compared different aerosol delivery approaches using an NIV model for children. They demonstrated that vibrating mesh nebulizers were superior to jet nebulizers for aerosol delivery. Mesh nebulizers, placed at the mask or before the Y-piece of the double-limb circuit, obtained a higher aerosol drug delivery. Given the paucity of evidence pertaining to aerosol inhalation during NIV, the results of this study are welcome as evidence for aerosol therapy during NIV.

Vibrating mesh nebulizers and jet nebulizers are commonly used devices for aerosol delivery with NIV. The vibrating mesh nebulizer is powered by electricity and does not add additional flow into the circuit. ${ }^{4,9}$ Therefore, the mesh nebulizer is unlikely to interfere with ventilator

The authors have disclosed no conflicts of interest.

Correspondence: Wei Ma PhD, Department of Respiratory Medicine, Guangzhou First People's Hospital, Guangzhou Medical University, 1 Panfu Road, Guangzhou, Guangdong, China. E-mail: mawei0311@126.com

DOI: $10.4187 /$ respcare.06059 function. The jet nebulizer, which is driven by compressed gas, is more likely to affect trigger synchrony. ${ }^{4,9,10}$ The

\section{See the Original Study on Page 141}

vibrating mesh nebulizer yields a higher pulmonary deposition rate compared with the jet nebulizer (3.8- to 4.7fold), based on the findings of Velasco and Berlinski. ${ }^{8}$ These findings are consistent with the previous study conducted by White et al ${ }^{11}$ These 2 studies, collectively, indicate that vibrating the mesh nebulizer is a preferable choice during NIV, but this should not be extrapolated to invasive ventilation.

The nebulizer position affects aerosol delivery efficiency during mechanical ventilation. ${ }^{12,13}$ At the initiation of inspiration, some of the aerosol diffuses in the expiratory limb, and is blown away during expiration, leading to the decreased aerosol delivery. ${ }^{13}$ During invasive ventilation, the circuit can serve as storage, ${ }^{13,14}$ thus decreasing aerosol loss during expiration. Therefore, the nebulizer should be distant from the patient during invasive ventilation. During NIV, the storage function of the circuit is poor due to gas leakage and flow through the circuit with leak compensation. Thus, when the nebulizer is distant from the patient, the effect of gas leakage on aerosol loss is greater; therefore, placing the nebulizer adjacent to the interface yields a higher pulmonary deposition. ${ }^{8}$ These findings are consistent with the previous study conducted by White et $\mathrm{l}^{11}$ in pediatric subjects and the study by Ball et $\mathrm{al}^{15}$ in adults.

However, the mechanisms explaining the effect of nebulizer position and the aerosol delivery efficiency require further investigation. A prudent approach would be to balance the effect of expiration and leakage.

It has been reported that aerosol delivery efficiency is increased with increasing inspiratory pressure levels and decreased with increasing expiratory pressure levels. ${ }^{6} \mathrm{Su}$ therasan et $\mathrm{al}^{12}$ found that aerosol delivery efficiency was higher with inspiratory/expiratory pressures $15 / 5 \mathrm{~cm} \mathrm{H}_{2} \mathrm{O}$ pressure compared to $10 / 5 \mathrm{~cm} \mathrm{H}_{2} \mathrm{O}$ and $20 / 10 \mathrm{~cm} \mathrm{H}_{2} \mathrm{O}$. However, Velasco and Berlinski ${ }^{8}$ reported in their study that increasing inspiratory positive airway pressure did not improve aerosol delivery efficiency. The results from these 


\section{EDITORIALS}

3 studies are in conflict, illustrating that the relationship between inspiratory/expiratory pressures and aerosol delivery efficiency is unclear.

An appropriate pressure may help increase the aerosol delivery efficiency. A concern with these studies is assessing an appropriate inspiratory and expiratory pressure based on in vitro experiments. During the application of NIV, the inspiratory and expiratory pressures should be adjusted according to the comfort and tolerance of the patient. Obviously, it is impossible to evaluate the comfort level and tolerance of patients receiving NIV based on in vitro experiments. Hence, it is challenging to determine the optimal inspiratory and expiratory pressures that might be used clinically. Thus, whether it is appropriate to assess the effect of inspiratory and expiratory pressures on the pulmonary deposition based on in vitro experiments remains to be determined.

An integrated aerosol inhalation regimen with NIV should include the selection and positioning of the nebulizer, selection of the ventilator circuit, the type and dose of drugs, ventilator parameters, and aerosolization time. The in vitro experiments conducted by Velasco and Berlinski ${ }^{8}$ provide guidance for the selection of an optimal aerosol inhalation procedure for pediatric NIV. If used appropriately, aerosol therapy can be delivered effectively during NIV.

\section{Gang Xu PhD Wei Ma PhD \\ Guangzhou First People's Hospital Guangzhou Medical University Guangdong, People's Republic of China}

\section{REFERENCES}

1. Basnet S, Mander G, Andoh J, Klaska H, Verhulst S, Koirala J. Safety, efficacy, and tolerability of early initiation of noninvasive positive pressure ventilation in pediatric patients admitted with status asthmaticus: a pilot study. Pediatr Crit Care Med 2012; 13(4):393-398.

2. Fanning JJ, Lee KJ, Bragg DS, Gedeit RG. U.S. attitudes and perceived practice for noninvasive ventilation in pediatric acute respiratory failure. Pediatr Crit Care Med 2011;12(5):e187-e194.

3. Castro-Codesal ML, Dehaan K, Featherstone R, Bedi PK, Martinez $\mathrm{CC}$, Katz SL, et al. Long-term non-invasive ventilation therapies in children: a scoping review. Sleep Med Rev 2017 [Epub ahead of print] doi: 10.1016/j.smrv.2017.02.005.

4. Dhand R. How should aerosols be delivered during invasive mechanical ventilation? Respir Care 2017;62(10):1343-1367.

5. Fink J, Ari A. Aerosol delivery to intubated patients. Expert Opin Drug Deliv 2013;10(8):1077-1093.

6. Chatmongkolchart S, Schettino G, Dillman C, Kacmarek R, Hess D. In vitro evaluation of aerosol bronchodilator delivery during noninvasive positive pressure ventilation: effect of ventilator settings and nebulizer position. Crit Care Med 2002;30(11):2515-2519.

7. Abdelrahim ME, Plant P, Chrystyn H. In-vitro characterization of the nebulized dose during noninvasive ventilation. J Pharm Pharmacol 2010;62(8):966-972.

8. Velasco J, Berlinski A. Albuterol delivery efficiency in a pediatric model of noninvasive ventilation with double-limb circuit. Respir Care 2018;63(2):141-146.

9. Dolovich MB, Dhand R. Aerosol drug delivery: developments in device design and clinical use. Lancet 2011;377(9770):1032-1045.

10. Ari A, Fink JB, Dhand R. Inhalation therapy in patients receiving mechanical ventilation: an update. Aerosol Med Pulm Drug Deliv 2012;25(8):319-332.

11. White CC, Crotwell DN, Shen S, Salyer J, Yung D, Zheng J, DiBlasi RM. Bronchodilator delivery during simulated pediatric noninvasive ventilation. Respir Care 2013;58(9):1459-1466.

12. Sutherasan Y, Ball L, Raimondo P, Caratto V, Sanguineti E, Costantino $\mathrm{F}$, et al. Effects of ventilator settings, nebulizer and exhalation port position on albuterol delivery during non-invasive ventilation: an in-vitro study. BMC Pulm Med 2017;17(1):9.

13. Ari A, Areabi H, Fink JB. Evaluation of aerosol generator devices at 3 locations in humidified and non-humidified circuits during adult mechanical ventilation. Respir Care 2010;55(7):837-844.

14. Ari A, Atalay OT, Harwood R, Sheard MM, Aljamhan EA, Fink JB. Influence of nebulizer type, position, and bias flow on aerosol drug delivery in simulated pediatric and adult lung models during mechanical ventilation. Respir Care 2010;55(7):845-851.

15. Ball L, Sutherasan Y, Caratto V, Sanguineti E, Marsili M, Raimondo $\mathrm{P}$, et al. Effects of nebulizer position, gas flow, and CPAP on aerosol bronchodilator delivery: an in vitro study. Respir Care 2016;61(3): 263-268. 